\title{
FORMS AND FUNCTIONS OF OPERATORS FOUND IN TWILIGHT NOVEL
}

\author{
Herman Paseru \\ Warmadewa University \\ hermanpaseru@gmail.com \\ I Wayan Ana \\ Warmadewa University \\ ana.wayan@gmail.com \\ Dewa Ayu Kadek Claria \\ Warmadewa University \\ clariadewaayu@gmail.com
}

\begin{abstract}
This research tries to analyze and discuss about the forms and functions of the operator in English found in the novel entitled Twilight written by Stephanie Meyer as the data source. The method used in conducting this research includes; chose the data source, data collection and data analysis. All the data from the novels are collected through library research by selecting the sentences which are related to the topic and analyzed systematically based on its types and functions. The theories applied to support this paper are the theory of Quirk, et al in their book entitled A Grammar of Contemporary English (1972) as the main theory, the theory of Cobuild in his book entitled English Grammar (1990) and others that are relevant to the topic are used as supporting theories. Based on the result of the analysis, it is found that the operators have four major forms namely do, be, have, and central modals. Besides, the functions of the operators are helping the positive declarative sentence in forming negative, interrogative, and nonassertive. In forming negative, the operator is immediately added with the negator not or the enclitic contracted form n't and it is placed between the subject and the predication. Then, there are two forms of interrogatives or questions, namely yes-no questions and wh-questions. In yes-no questions, operatoris placed in front of the subject generally and in the wh-questions, the operator follows the wh-words. Besides, the operators also have important function in forming the nonassertive because the nonassertive form usually appears in the negative and interrogative sentences.
\end{abstract}

Keywords: operator, form of operators, sentences, interrogatives, questions

\section{INTRODUCTION}

Nowadays, understanding English well and correctly cannot only ease us to communicate with other person in foreign countries, but it is also used for transferring the science and technology which are commonly written in English. Besides, English is also used in formal situations like seminar, academic activities, and speech. If we are talking about writing English, it is closely related to grammar, because grammar is a rule to make a good sentence. We could not avoid grammar as the rules in using language. The word grammar is used in many different senses. Grammar as we mean it is simply your language knowledge. What- 
ever your brain knows that allows you to use language we will call your grammar. Your grammar is what enables you to understand the very words you are now reading as well as to speak and write words and sentences of your own. In the basis of grammar, we could understand better about sentence arrangements. As we know, correct sentences are very essential in communication, wrong sentences cause misunderstanding between the writer and the reader or the speaker and the listener. Sentence is a group of words which express a statement, question or command. A sentence usually has a verb and a subject, and may be a simple sentence, consisting of one clause, or a complex sentence, consisting of two or more clauses. Some grammarians also give a certain definitions about sentence. Swan in his book entitled Practical English Usage (1995), defines that: Sentence is a group of words that expresses a statement, command, question or exclamation and consists of one or more clauses, and usually has at least one subject and verb. In writing, it begins with a capital letter ends with a full stop, question mark, or exclamation mark (1995).

A sentence is a group of words which makes complete sense (Murthy, 2003: 221). A sentence is a group of words which makes complete sense. It is the highest-ranking unit of grammar, sentence is an indeterminate unit in the sense that it is often difficult to decide, particularly in spoken language, where one sentence ends and another begins (Quirk \& Greenbaum, 1985: 47). Meanwhile, Cobuild also defines that sentence is a group of words which express a statement, question or command (Cobuild, 1990). A sentence usually has a verb and a subject, and may be a simple sentence, consisting of one clause, or a complex sentence, consisting of two or more clauses.

The finite verb group contains a lexical verb as its head. This lexical verb may or may not be modified by auxiliary verbs. A verb group consisting of just a head without auxiliary modification called a simple finite verb group. A verb group with modification by auxiliary verbs called complex finite verb group. When we talk about the auxiliary, it will not get out of the use of auxiliary in a sentence. Auxiliary verbs are defined by characteristics such as their ability to form negative and interrogative sentences rather than by their ability to support another verb. Although the auxiliaries have different functions in the verb phrase, they have one important syntactic function in common when they occur initially in the finite verb phrase, such as "Will he ask any questions?; Is he asking any questions? ; Has he asked any questions?" The first auxiliary of the verb phrase is isolated from the rest of the predicate no matter how complex the verb phrase is. For this purely syntactic function of the auxiliaries we will use the generic term OPERATOR (Quirk, 1973). The negation of a simple sentence is accomplished by inserting not between the operator and the predication. In colloquial English, the negator occurs in an enclitic contracted form - n't (Quirk, 1973: 374). In making questions, the operator is immediately placed in front of the subject.

\section{METHOD}

Every scientific paper has method in analyzing the problem. Method is a way of doing something. It is used in solving the problems or to achieve something. There are some steps which are used in analyzing the problem, they are: data source, data collection, and data analysis. The data are taken from a novel entitled twilight written by Stephanie Meyer. (2009), as my data source. The data source were collected through the process of reading the novel. The relevant data 
are underlined and then written down in the data list. Then, the data are classified based on the topic of discussion, that is the operator. The data were analyzed using descriptive method.

\section{DISCUSSION \\ Forms of Operator}

The basic rule for forming interrogative is by putting an operator before the subject and a clause is made negative by adding not or suffix $n$ ' $t$ after its finite auxiliary verb. Generally, the operators have four major forms to make negative, interrogative, and nonassertive sentences namely do, be, have, and central modals.

1. Do

Do is a primary verb which has functions as a full verb or lexical verb and an operator. Here, do is analyzed as an empty or dummy operator in conditions where the construction requires an operator, but where there is no semantic reason for any other operator to be present. To perform the functions of operators $d o$ occurs in the variant forms of do, does, and did. In the novel, it is found that some negative sentences where $d o$ acts as the operator. For more details, the analysis of $d o$ as the operator can be seen in the following examples:

1) I don't think real love is there at first. (Meyer Stephenie, 2009: 31)

2) You don't need to apologize to me. (Meyer Stephenie, 2009: 49)

The examples above are negative sentences which have been using $d o$ as the operator. The informal enclitic $-n$ 't added to the operator for making negation. Based on the previous chapter, it is described that the negation of a simple sentence is accomplished by inserting not between the operator and the predication. The sentence (1) is a complex sentence which is used $d o$ as an operator. It is consisting of an independent clause and a dependent clause. The independent clause contains the first singular person $I$ as the subject, the full verb think as the main verb, and an object $i t$. The operator $d o$ is added with the informal enclitic contracted form $n^{\prime} t$ after the subject $I$. The verb think is followed by the dependent clause real love is there at first functions as an object of this sentence.

The use of an operator do is also found in the sentence (2). The enclitic contracted form $n$ 't is inserted at the operator. Here, we can see that $n$ 't has been placed between the operator do and the predication need to apologize to me. This sentence is also a complex sentence where the independent clause contains the second singular person you as the subject which is placed in front of the operator, a lexical verb need as the main verb that is following an operator, and then it is continued by an object it. A dependent clause in form to infinitive namely to apologize to me which functions as an object. Those subjects of the sentences (1) and (2) use the first singular person $I$ and the second singular person you, besides the sentence are simple present. The dummy auxiliary do acts as the operator to make negation also used for the first plural pronoun we and the second plural pronoun they.

\section{2. $\mathrm{Be}$}

$B e$ functions as the operator occurs in the forms of am, is, are for present and was, were for past. It will be discussed in my analysis. From the data source, I found some negative sentences which use be as the operator. Those sentences 
can be seen below:

3) I am not trying to be your dad. (Meyer Stephenie, 2009: 31)

4) This isn't for school. (Meyer Stephenie, 2009: 18)

Those sentences above use be for making negation. $B e$ has a special form for the first singular person $I$ of the present namely am, we can be looked at the sentence (3). Here, am functions as the operator for operating the positive declarative sentence into negative sentence by inserting not between it and the predication. Before seeing the predication, the sentence consists of two main parts namely a subject $I$ and the predicate am not trying to be dad. The subject is placed in front of an operator am. The operator is followed by the verb try which is added with -ing form describes that the sentence is in progressive. By looking at this sentence, we should have know it is a complex sentence because there are independent clause and dependent clause. Independent clause have been pointed by $I$ as a subject, try as a main verb, and a direct object it. Meanwhile, the dependent clause in form to infinitive clause to be your dad functions as a direct object.

The simple sentence (4) uses is as the operator. Before becoming as the operator, it is a primary verb which functions as a main verb in the positive declarative sentence because there is not lexical verb here and for school acts as an adverbial of purpose which is located after the operator $i s$. The enclitic contracted form $n^{\prime} t$ is added with the operator is for forming the negation. The demonstrative pronoun this appears in front of the operator as the subject.

\section{Have}

Have is the verb in English which has two forms in present perfect and present perfect continuous (have, has). Have is also used in past perfect in form had and vice versa have as the operator occurs in the forms of have, has for present perfect and had for past perfect. These will be discussed in my analysis. In the novel, I found some negative sentences which introduces have as the operator. These can be looked at in the following examples:

5) I haven't been in the other room. (Meyer Stephenie, 2009: 11)

6) We haven't discussed your personal life before. (Meyer Stephenie, 2009: 29)

Those sentences above use operator have for making negation. It is accomplished by inserting not between the operator and the predication. The simple sentence (5) shows have as the operator in forming negation. The operator have which is added with the informal enclitic contracted form $n$ ' $t$ is inserted behind the subject $I$. The operator is followed by primary verb been as an auxiliary verb of this sentence. An adverbial of place in other room is located at the end of sentence. We can see again have becomes operator in the sentence (6). Here, an operator have is inserted between the first plural person we as the subject and the predication discussed your personal life before. The sentence is in perfect can be told through the using of have as the operator in forming negation and the showing of a lexical verb discuss in form past participle namely discussed as a main verb. The noun phrase your personal life which follows the verb plays as an object and it is continued by before which functions as an adverbial of time in this sentence.

\section{Central Modals}

The central modals form negation is also by inserting not between the operator and the predication. There are many negative sentences which introduce cen- 
tral modals as the operator in the novel. Some of them can be seen as below :

7) You can't put any more denials out there. (Meyer Stephenie, 2009: 208)

8) He couldn't be certain. (Meyer Stephenie, 2009: 187)

Those sentences above used the central modals to form negation. Starting from the sentence (7), operator can which is added with an informal enclitic contracted form $n$ 't to build negation. The operator can is inserted between the subject you and the predication any more denials out there. Based on the elements of sentence, the sentence contains the second singular person you as a subject, a lexical verb put as a main verb, an object any more denials, and an adverbial of place out there which is becoming an ending of the sentence. In the sentence (8), the operator could which is added with an informal enclitic contracted form $n$ 't forms the negation. This simple sentence shows could as the operator and it is placed behind the subject he. As we know that the modal auxiliary can act only as an auxiliary verbs, so an operator could is followed by a primary verb be which is acting as a main verb because a complement of subject certain follows the main verb.

\section{Functions of Operators}

\section{Forming Negative}

Generally the operators have four major basic forms namely do, be, have, and central modals. They have the essential function in forming negative sentences. The negation of a simple sentence is accomplished by inserting not between the operator and the predication. There are many negative sentences that include four major forms of operator but I only discuss some of them. They can be seen below:

9) I' $m$ not going to do anything to sabotage myself. (Meyer Stephenie, 2009: 113)

10) She and her mom weren't entitled to stay there (Meyer Stephenie, 2009: 35)

By looking at those negative sentences above, the function of operators in forming negation can be seen briefly. Generally, the negator is placed after the operator to operate positive into negative sentence. Let us begin from the sentence (9) which is using the special form am as the operator. In this sentence an operator am is not added with the negator but it is showed in an informal enclitic contracted form ' $m$ and it is added with the first singular person $I$ which acts as a subject. The negator not is placing between an operator and a predication going to do anything to sabotage myself. The lexical verb going which has been inserted with -ing form gives information that the sentence is in progressive. While to do anything to sabotage myself is a dependent clause in form to infinitive clause appears at the end as a complement of subject.

To operate positive into negative sentence, the sentence (10) performs were which added with an informal enclitic contracted form n't as an operator. The noun phrase she and her mom which has role as a subject shows in front of an operator were. We know that the sentence is in passive because an operator were is followed by the form of main verb is in past participle namely entitled. The to infinitive clause to stay there can be seen briefly after the main verb entitled as an adverbial of purpose of the sentence.

\section{Forming Interrogative}

Generally questions are sentences marked by placing of the operator immediately in front of the subject. Besides operating negative, Operators has im- 
portant function to help the declarative sentence in operating interrogative sentence. There are two forms of interrogatives or questions, they are yes-no questions and $w h$-questions. There are some interrogatives that belong to yes-no questions in the data source. They can be seen below :

11) Is he why you and Scott broke up? (Meyer Stephenie, 2009: 106)

12) Are you sure you shouldn't answer it? (Meyer Stephenie, 2009: 171)

$B e$ in variant form is shows at the first in the sentence (11) here, an operator is immediately has a place in front of the third singular person he which plays as a subject. The predication why you and Scott broke up follows the subject he in the sentence. It is a complement of subject of sentence which is built by dependent clause in form $w h$-clause.

The generic term operator in building interrogative sentence will be told again in the sentence (12). By presenting be in form are have been become the focus here. Are has an important role as an operator and it is followed by the second singular person you which appears as a subject. The sentence is categorized as complex where an independent clause before operating into question contains a subject you, a primary verb are which performs as a main verb, and a complement of subject sure. While the dependent clause you shouldn't answer it becomes an adverbial and ends the sentence.

\section{Forming Nonassertive}

Nonassertive forms usually appear in the negative and interrogative sentence. So, the operator has important function to help the declarative sentence in forming non assertion. It is signed with form any, any more, anything, anyone, anybody, anyway, yet, either, anywhere, at all, etc. There are some non assertions in form negative sentences in the data source. They can be seen below :

13) I' $m$ not countering with anything. (Meyer Stephenie, 2009: 115)

14) I wasn't like him to start anything without a game plan. (Meyer Stephenie, 2009: 53)

In the example above (13), the nonassertive form anything shows as a complement of subject. By explaining an operator am which is used in the sentence, being really certain that the sentence is in progressive especially there is a main verb counter inserted with -ing form follows the negator not. An operator am is pointed by an informal enclitic contracted form ' $m$ which merges with the subject I.

Sentence (14) is including a dependent clause in form to start anything without a game plan which plays as an adverbial of purpose. Without seeing the other elements, let us explore an adverbial of purpose which is behind an object $\mathrm{him}$. There is a nonassertive form anything within to infinitive clause. Then, we check an operator which is performed in this sentence namely was. Operator was is added with an informal enclitic contracted form $n$ ' $t$ and it is focused between the first singular person $I$ as a subject and a predication like him to start anything without a game plan.

\section{CONCLUSION}

The operators have four major forms to make negative, interrogative, and nonassertive namely do, be, have, and central modals. The dummy auxiliary do as 


\section{Kunlturisiolilk \\ KULTURISTIK JURNAL BAHASA \& BUDAYA}

Vol. 3, No. 1, Januari 2019, 30

Available Online at https://ejournal.warmadewa.ac.id/index.php/kulturistik

DOI: dx.doi.org/10.22225/kulturistik.3.1.936

the operator occurs in the variant forms of do, does, and did. Be as the operator occurs in the forms of am, is, are for present, and was, were for past. Have also occurs as the operator in forms of have, has, and had. Meanwhile, the central modals acts as the operator in many forms namely can, could, may, might, shall, should, will, would, and must.

The functions of the operators are helping the positive declarative sentence in forming negative, interrogative, and nonassertive. In forming negative, the operator immediately added with the negator not or the enclitic contracted form n't and it placed between the subject and the predication. The operators also has important function in operating interrogative. There are two forms of interrogatives or questions, namely yes-no questions and wh-questions. In yes-no questions, operator placed in front of the subject generally. Meanwhile, the operator follows the wh-words who, whom, whose, what, when, where, which, why, and how in the wh-questions. Then, the nonassertive forms usually appear in the negative and interrogative sentence. So, the operator has important function to help the sentence in making the nonassertive. It is signed with form any, any more, anything, anyone, anybody, anyway, yet, either, anywhere, at all, etc.

\section{REFERENCES}

Cobuild, C. (1990). English Grammar. London: Collins Publisher.

Meyer Stephenie. (2009). Twilight. New York: Little Brown.

Murthy, J. D. (2003). Contemporary English grammar for scholars and students. New Delhi: Book Palace.

Quirk, R., \& Greenbaum, S. (1985). A university grammar of English. England: Longman House Burnt Mill, Harlow.

Quirk, R. et al. (1973). A University grammar of English. London: Longman Group Ltd. 